\title{
SOBRE A IDENTIDADE NO TRACTATUS LOGICO-PHILOSOPHICUS ${ }^{1}$
}

Rogério Saucedo Corrêa (UFSM) ${ }^{2}$

rogeriosaucedo@ufsm.br

Resumo: No Tractatus Logico-Philosophicus, o sinal de identidade é excluído de qualquer uso significativo na linguagem porque expressões como " $a=a$ " e " $a=b$ " não podem ser proposições elementares e necessárias ao mesmo tempo. Por isso, a identidade é usada como uma operação. Esse uso não tem pretensões significativas, mas apenas indica o caráter intersubstituível dos sinais envolvidos.

Palavras-chave: identidade; operação; significado; proposição elementar.

\section{INTRODUÇÃO}

O Tractatus Logico-Philosophicus dá um tratamento especial para a identidade. Por um lado, critica determinado uso que é feito dela e, por outro lado, usa-a como uma operação. Comentadores como Marion (1998), Frascolla (1994; 2007), White (1978) e Fogelin (1983) abordaram aspectos dessa discussão. Marion, por exemplo, afirma que a eliminação do sinal de identidade, no Tractatus, é uma questão de simples transformação (MARION 1998, 51). Nesse ponto, ele comunga a interpretação de Ramsey, segundo a qual, o sinal de identidade não é um constituinte necessário da notação lógica e, portanto, pode ser substituído por uma

\footnotetext{
${ }^{1}$ Recebido: 26-03-2012/Aprovado: 12-02-2013/Publicado on-line: 27-02-2013.

${ }^{2}$ Rogério Saucedo Correa é Professor Adjunto da Universidade Federal de Santa Maria, Santa Maria, Rio Grande do Sul, Brasil.
} 
convenção em que sinais diferentes devem ter significados diferentes (RAMSEY 1931, 31). Creio, porém, que há um ponto a ser qualificado nessa posição, pois não se trata apenas de eliminar o sinal de identidade e sim de eliminá-lo de um uso específico, o uso que pretende significar um objeto. É apenas para os casos em que o sinal de identidade é usado com tal pretensão que ele deve ser eliminado, ou, melhor expresso, é esse uso que deve ser bloqueado. Para o uso do sinal de identidade em que não se pretende significar um objeto, é possível, como bem observa Ramsey, adotar convenções e o próprio Tractatus indica como isso pode ser feito. Nesses casos, a identidade deve ser entendida como uma regra de substituição.

Em Understanding Wittgensteins's Tractatus (2007), Frascolla faz duas afirmações importantes sobre a identidade no Tractatus. Em primeiro lugar, que o uso do sinal de identidade como uma regra de substituição é legítimo. Em segundo lugar, que o sinal de identidade não faz parte da linguagem que representa estados de coisas no Tractatus, pois expressões de identidade como " $a=a$ " e " $a=b$ " são excluídas da linguagem com sentido (FRASCOLLA 2007, 142). Por que, porém, expressões de identidade não fazem parte da linguagem com sentido? De acordo com Frascolla, expressões de identidade não fazem parte da linguagem com sentido porque a identidade não é uma relação objetiva e não o é (1) porque tentar explicar a expressão $(x)(f x \supset x$ $=a$ ) implica uma espécie de regresso infinito; (2) porque " $a$ $=b$ " não é uma proposição elementar e (3) porque é possível pensar em exemplos de objetos que não obedecem ao princípio da identidade dos indiscerníveis.

$O$ primeiro argumento para negar o caráter objetivo da identidade indica uma espécie de regresso ao infinito na 
explicação da expressão $(x)(f x \supset x=a)$, que é um resíduo da análise de uma frase contendo uma expressão denotativa. Suponha que o sinal "=" denota a relação I. Nesse caso, $(x)$ $(f x \supset x=a)$ assere que apenas os objetos que mantêm a relação I com $a$ têm a propriedade $f$. Isso, no entanto, é diferente de afirmar que apenas $a$ tem a propriedade $f$, exceto se $a$ for o único objeto que está para $a$ na relação I. Logo, se afirmo que a principal característica da relação I é que todo objeto mantém tal relação com ele mesmo e nada mais, não posso recorrer à noção de identidade, pois tentar individuar uma relação denotada pelo sinal de identidade pressupõe o sentido do sinal "=" como dado. O segundo argumento afirma que se a identidade for uma relação objetiva entre dois objetos em um estado de coisas, expressões como " $a=$ b" seriam proposições elementares, e, portanto, bipolares. Dada a falsidade de " $a=b$ ", em função do papel puramente referencial dos nomes genuínos no Tractatus, e se digo que duas coisas são uma e a mesma, não tenho apenas uma falsidade, mas um absurdo; se " $a=b$ " não for falsa, mas verdadeira, nesse caso, afirmo que um objeto é idêntico a ele mesmo. Logo, não tenho uma verdade contingente, mas uma verdade necessária. Por fim, o terceiro argumento mostra que é perfeitamente possível ter-se dois objetos que compartilham todas as suas propriedades formais, mas que, ainda assim, podem ser distinguíveis. Considerando que objetos são qualias e dado que as propriedades formais de um qualia são as suas possibilidades combinatórias, enquanto suas propriedades materiais são aquelas que ele possui em função de ser constituinte de determinado estado de coisas que ocorre, segue-se que dois qualias, que possuem a mesma forma, compartilham todas as suas propriedades formais e nada me impede de imaginar que existam propri- 
edades formais que um possui e o outro não, o que os torna distinguíveis.

Não pretendo disputar cada uma das proposições do argumento de Frascolla. Penso, no entanto, que as duas premissas que sustentam a recusa do caráter objetivo da identidade estão corretas ao passo que a última é controversa. Analisar essa tese, no entanto, exigiria uma discussão que foge do meu objetivo neste artigo. $\mathrm{O}$ ponto que me interessa diz respeito às razões para sustentar que expressões de identidade não fazem parte da linguagem com sentido. $\mathrm{O}$ argumento de Frascolla pode ser esquematizado da seguinte maneira:

1) $O$ sinal de identidade não faz parte da linguagem com sentido;

1. 2) Uma vez que expressões de identidade como " $a=a$ " $\mathrm{e}$ " $a=b$ " não fazem parte da linguagem com sentido;

3) e expressões de identidade não fazem parte da linguagem com sentido;

3.1) porque a identidade não é uma relação objetiva;

4) e a identidade não é uma relação objetiva;

4.1) porque tentar explicar a expressão $(x)(f x \supset x=a)$ implica uma espécie de regresso infinito;

4.2) porque “ $a=b$ ” não é uma proposição elementar;

4.3) porque é possível pensar em exemplos de objetos que não obedecem ao princípio da identidade dos indiscerníveis.

Frascolla está correto ao afirmar que o sinal de identi- 
dade não faz parte da linguagem com sentido porque expressões de identidade são excluídas da linguagem com sentido. No entanto, expressões de identidade não são banidas da linguagem com sentido apenas porque a identidade não é uma relação objetiva, mas porque enunciados de identidade não podem ser elementares e necessários ao mesmo tempo, e enunciados de identidade não podem ser elementares e necessários ao mesmo tempo por causa do princípio da independência lógica das proposições elementares, do princípio da independência do sentido em relação à verdade e à falsidade efetiva da proposição e dos princípios da completude da análise e do caráter determinado do sentido.

A segunda afirmação de Frascolla, que mencionei anteriormente, também está correta. $\mathrm{O}$ sinal de identidade é usado como uma regra de substituição em equações matemáticas. Essa posição, porém, indica uma mudança em relação à explicação do sinal de identidade formulada em "The Tractatus System of Arithmetics" (1997). Aqui, ao analisar o caráter das "proposições matemáticas", as equações são consideradas contrassensos porque o sinal de identidade assere uma relação semântica entre estruturas. Já analisei esse argumento em outro texto, por isso, não vou me deter nele e só indicarei os dois problemas básicos que ele implica (CORRÊA 2010, 235-236). Em primeiro lugar, é necessário observar que o Tractatus faz uma distinção básica entre descrever e nomear. Proposições elementares descrevem fatos, enquanto nomes significam objetos. Se o sinal de identidade asserisse a identidade entre estruturas, seguese que a identidade entre estruturas seria um fato. Logo, eu não precisaria explicar o funcionamento do sinal de identidade apenas no nível da linguagem, mas também da sua contraparte no mundo, pois os nomes significam objetos. 
Em segundo lugar, Frascolla ignora a verdadeira função do sinal de identidade nas equações que não é asserir uma relação entre estruturas, mas indicar a intersubstitutibilidade dos sinais que ladeiam o sinal de identidade. Expresso de outra forma, o sinal de identidade sinaliza uma operação. É interessante observar que essa é a posição de Frascolla em Understanding Wittgensteins's Tractatus (2007), mas não em "The Tractatus System of Arithmetics" (1997). Assim sendo, ou Frascolla mudou de posição de uma obra para outra ou manteve posições incompatíveis. Independentemente disso, a tese de que o sinal de identidade indica uma operação é a explicação correta do uso que dele faz-se no Tractatus.

No presente artigo, meu objetivo é duplo. Na primeira parte, analiso as razões para recusar-se que expressões como " $a=a$ " e " $a=b$ " sejam proposições elementares e necessárias ao mesmo tempo. Resumidamente " $a=a$ " não pode ser elementar e necessária ao mesmo tempo, uma vez que se for elementar, tem sentido. Logo, é uma proposição que descreve um estado de coisas e, consequentemente, não pode ser nem tautologia nem contradição, pois tautologia e contradição não descrevem estados de coisas. Se " $a=a$ ” não for tautologia, nem contradição, segue-se que não pode ser necessária, uma vez que apenas estas são necessárias. Por sua vez, " $a=b$ " não pode ser elementar, uma vez que as constantes lógicas nada significam. Se as constantes lógicas significassem, teríamos que admitir a existência de objetos lógicos. Considerando que proposições elementares são constituídas apenas por nomes simples, logicamente compatíveis entre si, e se " $a=b$ " for elementar, segue-se que "=" deve ser um nome simples que, desse modo, deve significar um objeto. Por sua vez, se "=" significa um objeto, em de- 
corrência, os demais conectivos lógicos também devem significar objetos. Tenho que admitir, portanto, a existência de objetos lógicos, os mesmos que causaram uma série de problemas para a teoria do juízo de Russell, como é o caso do problema da direção ${ }^{3}$. Uma consequência ainda mais grave seria a perda do caráter a priori da lógica. Com essa análise, portanto, qualifico tanto a explicação de Marion quanto a de Frascolla.

$\mathrm{Na}$ segunda parte do texto, o meu objetivo é mostrar que, enquanto regra de substituição, a identidade é uma operação. Aqui, o ponto central é concebê-la como um procedimento formal. Esse uso do sinal de identidade aparece na discussão sobre a definição de número. Nesse ponto, discordo da explicação de Frascolla, pois ele não concebe a identidade como um procedimento formal.

\section{“A $=A$ ” $E$ “ $A=B$ ” NÃO SÃO PROPOSIÇÕES ELEMENTARES}

As razões para negar-se que expressões como " $a=a$ " e " $a=$ $b$ ” sejam proposições elementares e necessárias estão associadas a quatro teses básicas: o princípio da independência lógica das proposições elementares; o princípio da independência do sentido em relação à verdade e à falsidade efetiva da proposição e os princípios da completude da análise e do caráter determinado do sentido. No que se segue, analiso cada uma dessas teses. Antes, porém, é interessante fazer uma observação.

As expressões " $a=a$ " e " $a=b$ " são exatamente as mesmas que estão em jogo no começo do artigo "Sobre o senti-

3 Russell (1996; 1999a e 1999b) trata desse problema em três textos. 
do e a referência", de Frege (1978). De acordo com Frege, a frase "A estrela matutina é a estrela vespertina" tem a forma de uma expressão de identidade. Desse modo, se substituo "A estrela matutina" e "A estrela vespertina" por " $a$ " e " $b$ ", respectivamente, então tenho " $a=b$ ". Uma vez que " $a=b$ " afirma que " $a$ " e " $b$ " são idênticos, devo poder substituir " $b$ " por " $a$ " em " $a=b$ " sem alterar o valor de verdade da frase original. $\mathrm{O}$ resultado dessa substituição é " $a=a$ ". Portanto, tenho:

1) " $a=a$ ": "A estrela matutina é a estrela matutina"

e

2) " $a=b$ ": "A estrela matutina é a estrela vespertina"

Todo problema, segundo Frege, é que (1) e (2) não parecem ter o mesmo conteúdo cognitivo. Enquanto " $a=$ $a$ " é uma verdade necessária, " $a=b$ " pode ser uma verdade contingente. Se assim é, não posso efetuar a substituição na frase original sem correr o risco de obter valores de verdade diferentes. Para explicar essa diferença, Frege recorre à distinção entre sentido e referência. Embora " $a=a$ " e " $a=$ $b$ " tenham a mesma referência, elas têm sentidos diferentes. " $a=a$ " e " $a=b$ " referem-se ao mesmo objeto (Vênus), mas o apresentam de modos distintos. A questão para Wittgenstein, no entanto, não é explicar a diferença de valor cognitivo entre essas expressões, visto que atribuir identidade a um objeto com ele mesmo não é dizer nada e afirmar que dois objetos são idênticos é um absurdo (WITTGENSTEIN 1994, 5.53030). A questão é saber se elas podem ser elementares e necessárias ao mesmo tempo. De modo geral, uma proposição só tem valor cognitivo, isto é, pretende afirmar algo com sentido sobre o mundo, se é 
elementar ou se é composta de proposições elementares. Como a resposta do Tractatus é negativa, em consequência, " $a=a$ " e " $a=b$ " devem ser retiradas da lista de candidatas a ocupar o lugar de proposições legítimas. Vejamos as razões.

Se assumo que " $a=a$ " é uma proposição elementar, então assumo também que ela é figurativa, posto que toda proposição elementar é um caso particular de figuração, ainda que nem toda figuração seja uma proposição ${ }^{4}$. Proposições elementares, portanto, descrevem, com sentido, fatos. Agora, se atribuo a noção tractariana de necessidade à " $a=$ a", o resultado é uma proposição elementar e necessária ao mesmo tempo. De modo geral, não parece haver nenhum problema com essa conclusão. A dificuldade surge, no entanto, quando ela é considerada à luz da tese da independência lógica das proposições elementares.

Uma proposição depende logicamente de outra se a sua verdade ou falsidade implica a verdade ou a falsidade da segunda e vice-versa. Desse modo, dizer que proposições elementares são logicamente independentes entre si significa dizer que a verdade ou falsidade de uma não implica a verdade ou falsidade de outra e vice-versa. Por que, porém, proposições elementares devem ser logicamente independentes entre si? Essa exigência é devida aos princípios da completude da análise e da independência do sentido em relação à verdade e à falsidade efetiva da proposição.

De acordo com o Tractatus, proposições complexas são definidas em termos de suas proposições elementares com-

\footnotetext{
${ }^{4} \mathrm{O}$ conceito de figuração é mais geral que o de proposição. Toda figuração para ser considerada como tal deve satisfazer certas condições. Deve possuir uma forma de afiguração, uma forma lógica, uma estrutura, regras de tradução, relações afigurantes e ser bipolar. Desse modo, se uma gravura, por exemplo, satisfaz estas condições, então, ela é uma figuração. Na verdade, o caso menos típico e que menos se parece com uma figuração é exatamente o caso das proposições. Todo esforço do Tractatus é mostrar que as proposições também satisfazem estas condições.
} 
ponentes (WITTGENSTEIN 1994, 4.4-4.41), que, por sua vez, são constituídas apenas e tão somente pela combinação de nomes simples logicamente compatíveis entre si (WITTGENSTEIN 1994, 3.141-3.23). A diferença entre proposições complexas e elementares assinala a diferença entre proposições instituídas mediante regras ou procedimentos formais e proposições instituídas mediante regras inscritas no mundo. Em outras palavras, assinala a diferença entre proposições construídas mediante operações e proposições figurativas. $\mathrm{O}$ processo figurativo começa, embora não se esgote, com as proposições elementares.

Operações são procedimentos formais para a construção de proposições (WITTGENSTEIN 1994, 5.23). Se o resultado da aplicação de uma operação for uma função de verdade, tem-se um caso particular de operação denominado operação de verdade (WITTGENSTEIN 1994, 5.234). Séries formais, por exemplo, são construídas mediante a aplicação reiterada de uma operação a uma base, em que a base pode ser obtida por enumeração ou por uma função. O primeiro caso é empregado quando se tem um número finito de proposições constituindo a origem da série. $\mathrm{O}$ segundo caso é adotado quando se tem um número infinito ou indeterminado de proposições constituindo a origem da série. Darei um exemplo desses dois casos na sequência, mas, antes, quero salientar quatro características importantes.

Em primeiro lugar, há uma diferença entre operação e operação de verdade (CUTER 2005, 63-65). A segunda é um caso particular da primeira. Em segundo lugar, no caso de uma operação de verdade, tenho base e origem da série. A base sempre será uma proposição retirada da origem da série. Em terceiro lugar, há dois modos diferentes de se ob- 
ter a base ${ }^{5}$, ou seja, tanto pode ser por enumeração quanto por uma função. $\mathrm{O}$ emprego de um ou outro modo dependerá de a origem da série ser ou não constituída por infinitas proposições (WITTGENSTEIN 1994, 5.501). Em quarto lugar, a aplicação reiterada da operação a sua base caracteriza o seu caráter recursivo e também o seu caráter formal. Um exemplo, em continuidade, será elucidativo para todos estes aspectos.

Suponha duas proposições elementares quaisquer " $p$ ” $\mathrm{e}$ " $q$ " 6 . Posso, nesse caso, obter " $p \& q$ " ou " $p$ Ú $q$ " mediante operações. Cada uma delas é uma função de verdade das suas proposições componentes, uma vez que os seus valores de verdade são dados a partir dos valores de verdade das suas proposições componentes, de modo que, em função disso, têm-se operações de verdade e não apenas operações. Nesses dois casos, as operações são indicadas pelos sinais para os conectivos de conjunção e disjunção. Sinais para conectivos lógicos, portanto, são indicadores de operações. Em “p \& q”, por exemplo, há apenas e tão somente duas proposições e, por isso, posso enumerá-las e obter a proposição molecular a partir delas. Outro aspecto importante é que eu poderia aplicar a conjunção novamente e obter algo como “( $p \& q) \&(p \& q)$ ”. Que seja possível fazer isso, mostra que a operação tem um caráter recursivo. A operação não tem apenas um caráter recursivo, mas também formal o que é relevante por duas razões. Primeiro, porque a operação não é um procedimento cujo resultado acrescenta algum conteúdo material às proposições envolvidas. Segundo, porque esse aspecto inócuo da operação só é possível por-

\footnotetext{
${ }^{5}$ Há um terceiro caso que diz respeito à especificação de uma lei formal, mas que ignoro aqui. 6 "p" e "q" não são proposições elementares, mas esquemas proposicionais.
} 
que ela não é aplicada a proposições propriamente ditas, mas a estruturas proposicionais ${ }^{7}$. Quando aplico a operação de conjunção para obter “p \& $q$ ”, a base está presente tanto na primeira aplicação da operação quanto no resultado, ou seja, se considero " $p$ " como base, ela aparece tanto no começo quanto no final. Mas isso só se torna patente se explicito a regra com a qual construí “ $p \& q$ ”. A regra, portanto, nada mais é do que a operação. No caso em questão, a regra seria algo como "se $x$ é a base, então ' $x \&$... é o resultado", onde se tem uma relação entre estruturas proposicionais. Por isso, não há nenhum acréscimo de conteúdo ao resultado. $\mathrm{O}$ que acontece, porém, quando tenho um número infinito ou indefinido de proposições compondo a origem da série?

Se a origem da série for constituída por um conjunto infinito ou indefinido de proposições, não posso simplesmente enumerá-las. Assim sendo, é necessário recorrer a uma função para selecionar uma proposição que será a base da série. Dessa forma, por exemplo, se a origem for o conjunto " $[f a, f b, f c, f g, . . .$,$] ", recorro a uma função do tipo " f x$ " para atuar sobre as proposições. $O$ detalhe fundamental, nesse caso, é que as proposições que compõem a origem da série possuem alguma propriedade formal em comum, o que é indicado por " $f x$ ", pois é a partir dessa função que todas as proposições são obtidas. Se a função não fosse " $f x$ ", mas "gx", a origem da série seria constituída por outras proposições que compartilham outra propriedade formal; seria algo como "[ga, gb, gc, ...,]". Aqui, portanto, tem-se um caso de operação e não de operação de verdade, devendo-se observar que essa peculiaridade não estava presente no pri-

\footnotetext{
${ }^{7}$ Estruturas proposicionais ou esquemas proposicionais.
} 
meiro caso porque se tratava de um conjunto enumerável de proposições. Mas qual a relevância dessa discussão para a análise sobre a identidade?

Estas considerações são importantes porque a identidade é uma operação ao passo que tautologia e contradição são construídas por intermédio de operações de verdade. Por causa disso, tanto em um caso quanto no outro, tenho procedimentos de caráter eminentemente formal. No entanto, se o resultado de usar uma operação qualquer para construir uma tautologia resulta em uma função de verdade, o mesmo não acontece ao usar-se a identidade. O caráter formal da tautologia é o que a distingue das proposições elementares. Expresso de outro modo, uma vez que tautologia e contradição são construídas por procedimentos formais e proposições elementares não o são, segue-se que a diferença entre elas reside no emprego ou não desse procedimento formal. No caso da tautologia e da contradição, há um aspecto adicional importante que se trata do caráter necessário que elas possuem. Quando aplico uma operação a uma base e obtenho uma proposição cujo valor de verdade, em cada caso, é sempre verdadeiro, tenho uma tautologia; caso o valor de verdade seja, em cada caso, falso, tenho uma contradição. Obtenho, portanto, proposições incondicionalmente verdadeiras ou incondicionalmente falsas (MACHADO 2007, 112). Dessa forma, posso afirmar que elas não possuem condições de verdade. Assim sendo, isto é, se elas não possuem condições de verdade, elas não descrevem estados de coisas. Uma vez que elas não descrevem estados de coisas, elas não têm sentido. Posso, no entanto, reconhecer, em uma tautologia ou contradição, a regra com a qual elas foram construídas, ou seja, a regra que me mostra quando estou diante de uma tautologia ou de uma con- 
tradição. Dado que a regra é, por assim dizer, uma explicitação da operação usada em cada caso e como a operação é um procedimento formal cujo resultado é uma "proposição” necessariamente falsa ou necessariamente verdadeira, segue-se que o caráter necessário da tautologia e da contradição está fundado no caráter formal da operação. Nada disso, porém, acontece com as proposições elementares formadas por nomes simples que significam objetos simples, mediante um processo que denomino instauração da figuração. Tal processo requer o cumprimento de uma série de condições para ser efetivado de modo que eu possa afirmar que tenho uma proposição figurativa. Contudo, não entrarei nos detalhes dessa discussão. Basta afirmar que uma proposição elementar é uma figuração se e somente se além de ser formada apenas por nomes simples, possuir forma de afiguração, forma lógica de afiguração, estrutura, regra de tradução, relação afigurante e for bipolar. $\mathrm{O}$ que aconteceria caso uma proposição elementar não contivesse apenas nomes simples? A resposta imediata é: aconteceria uma indeterminação do sentido proposicional.

Suponha que " $p$ " não possui apenas nomes simples, mas tenha também o nome de um complexo. Se isso acontecer, o sentido de " $p$ " estará indeterminado, e se o sentido de " $p$ " estiver indeterminado, a sua análise não terá um término. Se "p" possui um nome de complexo, é necessário que exista outra proposição elementar " $q$ " que descreva este complexo, uma vez que complexos são estados de coisas e estados de coisas só podem ser descritos. Se for assim, " $q$ " deve ser verdadeira, pois, caso contrário, o complexo não existe. Sendo assim, se o complexo não existe, segue-se que o seu correlato em "p", isto é, o nome do complexo não tem significado. Consequentemente, o sentido de " $p$ " não 
está determinado. Se "q" não for falsa, mas verdadeira, o sentido de " $p$ " dependerá da verdade efetiva de " $q$ ". Nos dois casos, o princípio da independência do sentido em relação à verdade e à falsidade efetiva da proposição é violado ${ }^{8}$.

Esse princípio, que se enunciou, não é uma prerrogativa do Tractatus. Na verdade, ele é a moral geral extraída da aplicação do método de análise da teoria das descrições definidas ${ }^{9}$. O problema, para o qual Russell formulou o método, envolvia exatamente casos em que as condições de verdade de uma proposição também eram as suas condições de sentido. De acordo com a teoria da denotação dos Principles of Mathematics (RUSSELL 1951, 53-65), expressões denotativas denotam objetos genuínos apenas porque contribuem para a constituição do sentido das frases em que ocorrem. Se devo pressupor a existência de objetos porque a frase contém uma expressão denotativa, então posso expressar essa condição. No caso da frase "o rei da França é calvo", por exemplo, a condição de existência é expressa pela frase "o atual rei da França existe" que deve ser verdadeira. Para que ela seja verdadeira, o seu sentido deve ser assegurado. Mas, uma vez que a frase "o atual rei da França existe" possui uma expressão denotativa, segue-se que a existência do atual rei da França deve ser garantida para que a frase tenha sentido. Portanto, a condição de verdade torna-se condição de sentido, uma vez que, para se atribuir um sentido à frase "o atual rei da França existe", a sua verdade deve ser assegurada. Consequentemente, o sentido da frase "o rei da França é calvo" também passa a depender da

\footnotetext{
${ }^{8}$ Aqui, sigo o argumento de Cuter (1994, 143-145).

${ }^{9}$ Russell (1905).
} 
verdade da frase "o atual rei da França existe”. Em resumo, o sentido das frases passa a depender da verdade. $O$ problema com a identificação das condições de sentido com as condições de verdade é que isso viola o princípio da anterioridade lógica do sentido em relação ao valor de verdade efetivo da frase. Segundo este princípio, a atribuição de sentido a uma frase deve ser uma condição lógica para a atribuição de um valor de verdade, isto é, somente aquilo que faz sentido pode ser verdadeiro ou falso. Com o método de redução, porém, as condições de verdade não serão mais consideradas condições de sentido da frase original.

Se considero a frase "o atual rei da França é calvo", posso reescrevê-la como " $(\exists x)(F x \cdot G x:(y)(F y \supset x=y))$ ", onde "Fx" significa " $x$ é rei da França atualmente" e "Gx" significa " $x$ é calvo". Desse modo, a frase reescrita " $(\exists x)(F x . G x:(y)$ $(F y \supset x=y)$ )" é nada mais nada menos que a conjunção das duas condições de sentido da frase original; é a conjunção da condição de existência e da condição de unicidade. Na frase reescrita, porém, elas explicitam-se como condições de verdade. Se não existir um rei da França que seja calvo ou se existir mais de um rei da França que seja calvo, a frase será falsa. Mas, caso exista um e apenas um rei da França que seja calvo, a frase será verdadeira. Independentemente disso, porém, o sentido da frase está garantido. Além disso, a frase reescrita não contém mais a expressão denotativa, pois ela simplesmente afirma que "existe atualmente um rei da França que é calvo e não existe mais que um rei da França que é calvo", em que não ocorre mais nenhuma expressão denotativa do tipo "o rei da França”. Com esse procedimento, portanto, Russell dava conta dos problemas envolvidos na sua antiga teoria da denotação. É esse princípio que Wittgenstein incorpora a partir da teoria das descrições 
definidas de Russell e que está pressuposto na impossibilidade da nomeação de complexos. Nomear complexos, portanto, é estabelecer que o significado dos componentes da proposição depende da verdade das proposições que descrevem os complexos. A consequência disso, por sua vez, é a indeterminação do sentido da proposição na qual há nome de complexos, pois, se os complexos não existirem, os nomes não terão significado, consequentemente, as proposições das quais eles fazem parte não terão sentido.

A presença de nomes de complexos em uma proposição implica a indeterminação do seu sentido. Por isso, Wittgenstein afirma que o postulado da possibilidade dos sinais simples é o postulado do caráter determinado do sentido (WITTGENSTEIN 1994, 3.23). Não posso, portanto, violar o princípio da completude da análise e, sobretudo, violar o princípio da independência do sentido em relação à verdade e à falsidade efetiva da proposição.

Se, de acordo com o princípio da completude da análise, o significado dos nomes não pode depender de uma questão empírica, e se uma proposição elementar é formada pela combinação de nomes simples logicamente compatíveis entre si, o sentido de uma proposição elementar deve ser independente da verdade ou da falsidade efetiva, quer seja da própria proposição elementar quer seja de qualquer outra proposição, pois, caso contrário, ele dependeria de uma questão empírica. Uma vez que o sentido proposicional é dado pela possibilidade de existência ou inexistência dos estados de coisas que a proposição descreve, ou seja, por suas possibilidades de verdade, então as possibilidades de verdade de uma proposição elementar devem ser logicamente independentes das possibilidades de verdade de qualquer outra proposição. Proposições elementares, por- 
tanto, devem ser logicamente independentes entre si e disso segue-se que elas não são necessárias e que os estados de coisas também são independentes entre si.

Quais seriam, porém, as consequências de se aplicar o caráter elementar à tautologia e à contradição? Em primeiro lugar, tautologia e contradição seriam consideradas contingentes, uma vez que proposições elementares podem ser verdadeiras ou falsas. Não seriam, portanto, necessariamente verdadeiras ou necessariamente falsas. Além disso, descreveriam situações possíveis no mundo, ou seja, seriam figurativas. Uma vez que seriam constituídas apenas por proposições elementares, segue-se que seriam formadas exclusivamente por nomes simples. Desse modo, os sinais que expressam noções lógicas, presentes nas tautologias e contradições, significariam objetos simples tanto quanto os demais nomes que as constituem. Os sinais lógicos, portanto, não indicariam aplicações de operações, mas, de algum modo, sinalizariam o acréscimo de conteúdo às proposições. Esse último ponto diz respeito ao Grundgedanke do Tractatus e serve para apresentar o argumento que explica porque " $a=b$ " não pode ser uma proposição legítima.

O Grundgedanke do Tractatus é a tese segundo a qual as constantes lógicas nada significam. Essa tese está associada à ideia de que apenas os nomes simples significam. Toda proposição elementar é uma figuração de um estado de coisas. Se uma proposição é uma figuração daquilo que ela figura, seus elementos substituem ou fazem às vezes dos objetos que compõem o estado de coisas. Aqui, o ponto importante é a distinção entre os verbos vertreten e darstellen, que caracterizam o modo como os nomes e as proposições funcionam. Os nomes representam (vertreten) os objetos, enquanto as proposições apresentam (darstellen) os estados 
de coisas. Um nome representa um objeto na medida em que substitui o objeto ou faz às vezes do objeto na proposição. A proposição, porém, apresenta um estado de coisas na medida em que "está para" o estado de coisas. A diferença entre representar e apresentar é que, na representação, a substituição pressupõe que o objeto substituído pelo nome esteja dado de antemão, enquanto que, na apresentação, a proposição não substitui o estado de coisas figurado, pois um estado de coisas não precisa ocorrer para que possa ser descrito. A proposição, dessa maneira, apresenta um estado de coisas em uma concatenação de nomes que substituem, na proposição, os objetos que esses nomes significam e, assim, fazendo, a proposição apresenta uma concatenação possível desses objetos. Se a concatenação ocorre, a proposição é verdadeira; caso contrário, ela é falsa. A proposição, portanto, é a apresentação de uma concatenação possível de objetos por meio da concatenação efetiva dos nomes desses objetos. Seus elementos estão combinados tal como os componentes do estado de coisas devem estar combinados, se a proposição for verdadeira. Dessa forma, os nomes que compõem a proposição necessariamente significam os objetos que constituem o estado de coisas de tal modo que, para cada nome, deve haver um e apenas um objeto designado.

Assim posto, considere a expressão " $a=b$ ". Se ela for elementar, deve descrever um estado de coisas. Para tanto, os seus componentes devem significar objetos simples. Não apenas " $a$ " e " $b$ " devem significar objetos, pois tanto "=" quanto os demais sinais para os conectivos lógicos também devem significar. Nesse sentido, "=" é um sinal para uma constante lógica assim como os demais conectivos lógicos do cálculo de predicados. Se as constantes lógicas significam, consequentemente, elas designam objetos. Nesse sen- 
tido, posso afirmar que os objetos significados por constantes lógicas são objetos lógicos, seja lá o que isso for. Devem existir, portanto, objetos lógicos significados por nomes. Wittgenstein estava consciente das implicações negativas dessa tese, assim como Ramsey que também sustentava que isso implicava a perda do caráter a priori da lógica ${ }^{10}$. $\mathrm{O}$ contexto geral da discussão de Ramsey é a constituição dos elementos de uma proposição crida por um sujeito. Quando tenho apenas uma proposição elementar, não há maiores problemas, pois ela é constituída apenas por nomes. Se, no entanto, tenho uma proposição molecular, ela não é constituída apenas por nomes, mas também por constantes. Nesse caso, é necessário explicar o significado das constantes, considerando-se, por exemplo, que uma explicação possível consiste em dizer que elas são nomes de relações. Logo, uma proposição em que ocorre a negação assere a relação de negação mais os termos simples. A título de exemplo, a proposição "Isto não é vermelho" assere a relação de negação entre "isto" e "vermelho". Por sua vez, "Isto não é não vermelho" assere outra relação de negação com a primeira negação e "vermelho" e, assim, sucessivamente. Se aceito que a negação nomeia uma relação, cada vez que a aplico, estou asserindo um novo fato. Consequentemente, estou asserindo "fatos necessários", caso se trate de uma tautologia. Logo, uma proposição lógica qualquer diz respeito a fatos e, a lógica, em última instância, também é concernente a fatos. Assim entendida, ela perde o seu caráter a priori. $\mathrm{O}$ argumento de Ramsey, nesse ponto, é muito semelhante ao de Wittgenstein, mas ele contém uma premissa oculta. Trata-se de afirmar que nomear relações é en-

${ }^{10}$ Ramsey $(1931,146)$ discute esse ponto ao criticar a concepção de lógica de Chadwick. 
tificar relações, pois nomes nomeiam objetos e se uma constante nomeia um objeto, ela nomeia algo que é portador de ser. É bem verdade que, na sequência do seu texto, Ramsey acaba afirmando que a negação não pode nomear objetos, mas, ainda assim, é necessário esclarecer que nomear uma relação significa entificá-la. Um aspecto, portanto, que está pressuposto na posição de Wittgenstein é a recusa em abrir mão do caráter a priori da lógica.

É interessante observar que Ramsey não atribui a Russell a concepção descrita anteriormente, mas ela adequar-se-ia perfeitamente a ele, visto que um dos pontos principais das teorias do juízo de Russell é a entificação das relações. De acordo com Griffin (1985), Russell sustentou três teses básicas, seja na teoria do juízo como relação dual, seja na teoria do juízo como relação múltipla ${ }^{11}$. A tese da intencionalidade afirma que todo evento mental possui objetos, considerando-se, dessa forma, que juízos são eventos mentais, segue-se que eles possuem objetos. A tese realista, por sua vez, afirma que todo objeto possui ser. Desse modo, se todo evento mental possui objetos e se todo objeto possui ser, segue-se que todos os objetos de um evento mental possuem ser. Uma vez que o objeto de um juízo é uma proposição, ela possui ser. Considere, neste sentido, como exemplo o juízo de Pedro acerca do amor de Maria por Carlos. Do ponto de vista da teoria do juízo como relação múltipla, esse juízo é uma relação múltipla entre o sujeito e cada um dos componentes do complexo julgado que é a proposição "Maria ama Carlos". Cada um dos elementos que a compõe deve ser considerado como

\footnotetext{
${ }^{11}$ Ignoro a tese da verdade como correspondência, pois não é necessário analisá-la para os meus propósitos.
} 
um objeto portador de ser. Esta é, inclusive, a diferença básica entre a teoria do juízo como relação múltipla e a teoria do juízo como relação dual, pois, para a última, a relação dá-se entre o sujeito e a proposição considerada como um todo que, como tal, deve ser um objeto portador de ser. Para a primeira, porém, o juízo é uma relação múltipla com cada um dos objetos que compõe a proposição julgada. Não é difícil estender essa tese para o caso de uma proposição complexa como "Maria ama Carlos e Pedro ama Maria”. Suponha, portanto, que Pedro julga que Maria ama Carlos e Pedro ama Maria. Nesse caso, o juízo é a relação com cada um dos componentes da proposição "Maria ama Carlos e Pedro ama Maria”. Como essa proposição contém um conectivo lógico de conjunção e como cada componente da proposição é portador de ser, segue-se que o conectivo lógico de conjunção diz respeito a um objeto lógico, sendo que o mesmo vale para os demais conectivos lógicos. Portanto, as relações são entificadas e existem certas entidades chamadas objetos lógicos.

Para Wittgenstein, assumir que é possível significar e que existam objetos lógicos é assumir que a lógica não é a priori, pois os sinais para noções lógicas teriam, neste aspecto, que significar objetos lógicos. Como os sinais lógicos não podem significar objetos lógicos sob pena de a lógica perder o seu caráter a priori, a alternativa é considerá-los com sinais que indicam operações tal como mostrei em passagem anterior. Assim sendo, ainda que a contradição e a tautologia sejam construídas a partir de proposições elementares, o procedimento para obtê-las é puramente formal e o resultado desse procedimento é uma proposição que é incondicionalmente verdadeira ou incondicionalmente falsa, significando, pois, que elas não são figurativas. Assim 
como o sinal de conjunção, por exemplo, não pode significar um objeto lógico, o sinal de identidade também não pode. Se isso fosse possível, o sinal de identidade deveria significar certo objeto lógico correlato ao sinal de identidade. Como não pode existir tal objeto, usar a expressão " $a=$ $b$ " para dizer algo com sentido sobre o mundo é um absurdo.

\section{A IDENTIDADE COMO UMA OPERAÇÃO}

Como mostrei anteriormente, uma consequência da crítica ao uso pretensamente significativo da identidade é o seu respectivo banimento da linguagem com sentido. Há dois pressupostos gerais nessa discussão. Em primeiro lugar, a tese de que, para cada símbolo, há um e apenas um objeto e vice-versa, o que está intimamente relacionado com a teoria da figuração. Em segundo lugar, expressões em que o sinal de identidade é usado com pretensões significativas podem ser reescritas sem ele. Se isso é correto, segue-se que o sinal de identidade não é essencial em uma notação. Um exemplo disso é a expressão ' $f(a, b), a=b$ ' que pode ser escrita como ' $f(a, a)$ ' (WITTGENSTEIN 1994, 5.531-5.534).

Mas, se o sinal de identidade não pode ser usado para significar um objeto, resta algum uso legítimo para ele? A resposta do Tractatus é considerá-lo uma regra de substituição. Dois exemplos disso aparecem nos aforismos $6.02 \mathrm{e}$ $6.241^{12}$. No primeiro caso, o contexto é a definição de número como expoente de operações. No segundo caso, é a demonstração de uma multiplicação. Analiso apenas o primeiro caso, pois ele é mais simples. Dadas duas definições,

\footnotetext{
${ }^{12}$ Frascolla $(1994,14-19)$ apresenta uma análise da demonstração de "2 × 2 = 4".
} 
posso construir a série formal em que os números aparecem como expoentes, ou seja, dadas as definições

1) $x=\Omega^{0^{\prime}} x$ Def.

$\mathrm{e}$

2) $\Omega^{\prime} \Omega^{v^{\prime} x}=\Omega^{v^{+1}} x$ Def.

e dada a série formal

a) $x, \Omega_{x}^{\prime}, \Omega^{\prime} \Omega_{x}^{\prime}, \Omega^{\prime} \Omega^{\prime} \Omega_{x}^{\prime}, \ldots$,

obtenho a série formal

b) $\Omega^{0} x, \Omega^{0+1} x, \Omega^{0+1+1} x, \Omega^{0+1+1+1} x, \ldots$

Ignoro os detalhes da definição indutiva que está em jogo em 6.02, porque o meu ponto é ressaltar o papel do sinal de identidade em (1) e $(2)^{13}$. Neste sentido, a função da identidade pode ser expressa da seguinte maneira:

$\left.1^{\prime}\right)$ Se $x$ é substituível por $\Omega^{0^{\prime} x}$, então $\Omega^{0^{\prime}} x$ também é substituível por $x$.

$\left.2^{\prime}\right)$ Se $\Omega^{\prime} \Omega^{\mathrm{v}^{\prime} x}$ é substituível por $\Omega^{\mathrm{v}+1^{\prime}}$, então $\Omega^{\mathrm{v}+1^{\prime}}$ também é substituível por $\Omega^{\prime} \Omega^{\mathrm{v}^{\prime}}$.

O papel da identidade é indicar que as expressões que a ladeiam são intersubstituíveis em determinados contextos. Ela não significa, portanto, nenhum objeto, mas apenas e tão somente expressa uma regra de substituição. Neste sentido, a identidade pode ser considerada uma operação, mas não uma operação de verdade. Se a variável $x$ está para uma

\footnotetext{
${ }^{13} \mathrm{O}$ leitor encontrará uma análise mais detalhada do funcionamento da definição por indução em Cuter (2005, 71-72) e Frascolla (1994, 8-12).
} 
proposição, então $\Omega^{\prime} x$ também é uma proposição, assim como $\Omega^{\prime} \Omega^{\prime} x$. Dado o valor de verdade de “x”, também está dado o valor de verdade de $\Omega^{\prime} x$. Mas isso não acontece em (1) ou em (2), pois $x=\Omega^{0^{\prime}} x$ não é uma função de verdade de $x$ assim como $\Omega^{\prime} \Omega^{v^{\prime} x}=\Omega^{v+1} x$ não é uma função de verdade de $\Omega^{\prime} \Omega^{v^{\prime} x}$, mas apenas indica que as expressões são intersubstituíveis. No entanto, esse procedimento tem um caráter eminentemente formal, pois não há nenhum acréscimo de conteúdo material a $\Omega^{0^{\prime}} x$.

É importante observar também que para se obter as séries formais em (a) e (b) não foi necessário mencionar o significado de "=", nem de nenhuma das expressões envolvidas no processo. A única coisa necessária foi fazer as substituições em (a) a partir das definições (1) e (2). O ponto fundamental, portanto, é que, no uso do sinal de identidade como uma regra de substituição, ele não é empregado para dizer algo com sentido sobre o mundo, mas simplesmente para indicar que, quando for o caso, posso colocar o definiens no lugar do definiendum e vice-versa. Não se trata, portanto, de simplesmente eliminar o sinal de identidade e fazer isso mediante simples convenção. Trata-se, em primeiro lugar, de se negar que o sinal de identidade possa ser usado para dizer algo com sentido sobre o mundo. Em segundo lugar, a eliminação não está assentada em uma mera convenção, mas depende fundamentalmente das condições mais básicas do conceito geral de figuração, em especial, depende da tese de que nomes significam e proposições descrevem ${ }^{14}$.

Abstract: The identity sign is excluded from any meaningful language use in

\footnotetext{
${ }^{14}$ Agradeço a César Schirmer dos Santos e a Rogério Passos Severo que lerem este artigo e fizeram várias observações.
} 
the Tractatus Logico-Philosophicus, because expressions such as " $a=a$ " and " $a=$ $b$ " cannot be elementary and necessary propositions at the same time. Hence, identity is used as an operation. That use does not intend to be meaningful, but only to indicate the interchangeable nature of the signs involved.

Keywords: identity; operation; meaning; elementary proposition.

\section{REFERÊNCIAS}

CORREAA, Rogério Saucedo. Matemática e conhecimento no Tractatus Logico-Philosophicus. In.: GALLINA, Albertinho Luiz; SARTORI, Carlos Augusto (org.). Ensaios de epistemologia contemporânea. Ijuí: Editora UNIJUÍ, 2010, p-223-242.

CUTER, João Vergílio Gallerani. Operations and truthoperations in the Tractatus. Philosophical Investigations. v. $28, \mathrm{n}^{\mathrm{o}} 1$, p. $63-75,2005 \mathrm{a}$.

- A teoria da figuração e a teoria dos tipos: o Tractatus no contexto do projeto logicista. 1993. $203 \mathrm{f}$. Tese (Doutorado em Filosofia) - Faculdade de Filosofia, Letras e Ciências Humanas, Universidade de São Paulo, São Paulo, 1993.

FRASCOLLA, P. Wittgenstein's philosophy of mathematics. London: Routledge, 1994.

. Understanding Wittgensteins's Tractatus. London: Routledge, 2007.

. The Tractatus System of Arithmetics. Synthese. $\mathrm{n}^{\mathrm{o}}$. 112, p. 353-378, 1997.

FOGELIN, R. J. Wittgenstein on identity. Synthese. n ${ }^{\circ} .56$, p. 141-154, 1983.

FREGE, G. Lógica e filosofia da linguagem. Trad. Paulo 
Alcoforado. São Paulo: Cultrix, 1978.

GRIFFIN, N. Russell's multiple relation theory of judgment. Philosophical Studies. v. 47, no 2, p. 213-247, 1985.

MACHADO, A. N. Lógica e forma de vida: Wittgenstein e a natureza da necessidade lógica e da filosofia. São Leopoldo: Editora da UNISINOS, 2007.

MARION, M. Wittgenstein, finitism, and the foundation of mathematics. Oxford: Clarendon Press, 1998.

RAMSEY, F. The foundations of mathematical and other logical essays. New York: Harcourt, Brace and Company, 1931.

RUSSELL, B. Principia mathemathica. v. 1. Cambridge: Cambridge University Press, 1968.

. The principles of mathematics. London: George Allen \& Unwin, 1951.

. Philosophical essays. London: Routledge, 1996.

. The problems of philosophy. Mineola: Dover Publications, 1999a.

. Theory of knowledge: the 1913 manuscript. London: Routledge, 1999b.

. On denoting. Mind. v. 14, nº 4, p. 479-493, 1905.

WITTGENSTEIN, L. Tractatus logico-philosophicus. Trad. Luiz Henrique Lopes dos Santos. São Paulo: EDUSP, 1993.

WHITE, R. W. Wittgenstein on identity. The Aristotelian Society. v. 78, p. 157-174, 1979. 
